\title{
VIVENCIANDO REPERCUSSÕES E TRANSFORMAÇÕES DE UMA GESTAÇÃO: PERSPECTIVAS DE GESTANTES
}

\author{
LIVING REPERCUSSIONS AND TRANSFORMATIONS OF \\ A PREGNANCY: PREGNANT'S PERSPECTIVE
}

\section{VIVIENDO REPERCUSIONES Y TRANSFORMACIONES DE UN EMBARAZO: LA PERSPECTIVA DE EMBARAZADAS}

\author{
Karla Gonçalves Camacho* \\ Octavio Muniz da Costa Vargens ${ }^{* *}$ \\ Jane Márcia Progianti ${ }^{* * *}$ \\ Thelma SPÍNDOLA ${ }^{* * *}$
}

\begin{abstract}
RESUMO
Pesquisa descritiva, abordagem qualitativa baseada nos pressupostos do Interacionismo Simbólico e da Grounded Theory, estuda a gravidez como período de adaptações físicas e emocionais. Objetivou-se identificar o significado das transformações do período gestacional, sob o ponto de vista da gestante, que influenciam em sua identificação como mãe. Os dados foram obtidos em 2005, com entrevistas semi-estruturadas, no pré-natal de um Centro Municipal de Saúde, do Rio de Janeiro. A análise comparativa constante permitiu a construção de duas categorias cuja integração em suas diferentes dimensões possibilitou identificar a categoria central: vivenciando repercussões e transformações de uma gestação. Esta representa um processo ativo de busca pela identidade materna. Os resultados mostraram que transformações gestacionais repercutem diretamente na construção feminina da maternidade e na identidade da mulher como mãe.
\end{abstract}

Palavras chave: Enfermagem obstétrica, gravidez, adaptação, saúde da mulher.

\begin{abstract}
This is a descriptive and qualitative study based on the principles of Symbolic Interactionism and Grounded Theory. It approaches the pregnancy as a life period of physical and emotional adaptations. It aimed at identify the meaning of the pregnancy transformations, from the pregnant's point of view, and its influences in woman's identification as mother. Data were obtained in 2005, with semi-structured interviews, in the prenatal service of a Municipal Health Center in Rio de Janeiro-Brazil. The constant comparative analysis allowed the construction of two categories whose integration in their different dimensions made possible to identify the central category: living repercussions and transformations of a pregnancy. This represents an active process of searching for the maternal identity. The results showed that pregnancy's transformations influences directly in the feminine construction of the maternity and in the woman's identity as mother.
\end{abstract}

Key words: Obstetrical nursing, pregnancy, adaptation, women's health.

*Enfermeira. Mestre em Enfermagem pela Universidade do Estado do Rio de Janeiro (UERJ), Brasil. E-mail: pequenakgc@ yahoo.com.br e kgcamacho@gmail.com.

"Enfermeiro Obstetra;Professor Titular da Faculdade de Enfermagem da UERJ, Líder do Grupo de Pesquisas sobre Gênero, Poder, Violência na Saúde e Enfermagem. Rio de Janeiro, RJ, Brasil. E-mail: omcvargens@uol.com.br

${ }^{* * *}$ Enfermeira Obstétrica; Professora Adjunta da Faculdade de Enfermagem da UERJ, Brasil. E-mail: jmprogi@uol.com.br

*****Enfermeira Obstétrica. Professora Adjunta da Faculdade de Enfermagem da UERJ, Brasil. E-mail: spindola@centroin. com.br 


\section{RESUMEN}

Éste es un estudio descriptivo y cualitativo basado en los principios del Interaccionismo Simbólico y de la Grounded Theory. Es acerca del embarazo como un período de vida de adaptaciones físicas y emocionales, cuyo objetivo es identificar el significado de las transformaciones del embarazo, desde el punto de vista de la embarazada, y sus influencias en la identificación de esta mujer como madre. Se obtuvieron los datos en 2005, a través de entrevistas semiestructuradas, en un servicio prenatal de un Centro Municipal de Salud en Río de Janeiro-Brasil. El análisis comparativo constante permitió la construcción de dos categorías cuya integración en sus dimensiones diferentes hizo posible identificar la categoría central: la vivencia de las repercusiones y transformaciones de un embarazo. Esto representa un proceso activo de buscar la identidad materna. Los resultados mostraron las influencias de las transformaciones de ese embarazo directamente en la construcción femenina de la maternidad y en la identidad de la mujer como madre.

Palabras clave: Enfermería obstétrica, embarazo, adaptación, salud de la mujer.

Fecha recepción: 25/02/09 Fecha aceptación: 27/07/10

\section{INTRODUÇÃO}

A gravidez é um fenômeno diferenciado na vida de um casal, em que ambos passam por adaptações tanto físicas quanto emocionais. A mulher tem seu corpo modificado pelos efeitos hormonais e o homem adapta-se, ou pelo menos tenta adequar-se a estas mudanças (1).

As alterações que ocorrem durante a gravidez talvez sejam as mais significativas modificações que o ser humano pode sofrer. A gestação e o nascimento de uma criança são eventos psicossociais, que afetam profundamente a vida dos pais e das famílias (2). Estes eventos são essenciais, do ponto de vista da mulher e de sua família, para a construção da idéia de gestação e são favoráveis à adaptação, tanto da mulher quanto de sua procedência, às transformações decorrentes da gravidez, além de ajudá-la a manter sua saúde e prepará-la para o nascimento de seu filho $(2,3,4)$.

Dentre as alterações gestacionais, destacam-se as emocionais, que se caracterizam por oscilações de sentimentos e repercutem nas relações familiares, na satisfação dos casais e de seus filhos $(5,4)$. As alterações fisiológicas, assim como as emocionais, quando associadas à gestação podem ser significantes. Há também uma interação entre as transformações internas (não perceptíveis) e externas (visíveis) emitindo de uma forma particular reações nos protagonistas gestacionais. São tentativas de sucesso do corpo feminino para adaptar-se ao novo corpo em desenvolvimento no ventre materno.

A gravidez pode ser considerada então como uma fase marcada por um estado de tensão, devido à expectativa das grandes mudanças que estão e continuarão a acontecer, principalmente para a mulher que passa, então, a se ver e ser vista de maneira diferenciada, formando-se um novo papel: o de ser mãe (4).

Acontecem alterações hormonais muito importantes, marcadamente um aumento contínuo das concentrações de dois principais hormônios femininos: a progesterona $\mathrm{e}$ o estrogênio, até atingir valores muito elevados. Assim, pode-se entender que a gestação afeta praticamente todos os hormônios do organismo materno $(6,7)$.

São diversas as transformações que ocorrem no organismo da grávida, e estas estarão interferindo no dia a dia da mulher, incluindo sexualidade, prazer e relação a dois (8). As alterações fisiológicas associadas à gestação podem ser sutis ou marcantes. Embora sejam normais e necessárias podem ser desconfortáveis e até mesmo causar medo (3).

No primeiro trimestre, talvez a mulher possa não sentir grandes diferenças, pelo fato 
das mudanças estarem acontecendo apenas internamente, não expondo as alterações no corpo que acontecerão já no segundo trimestre. No segundo trimestre, com a gravidez mais estabilizada, a maioria das mulheres pode sentir uma melhora significativa na disposição, e algumas delas percebem até um aumento da libido. Quando a mulher entra no terceiro trimestre gestacional, geralmente a indisposição pode voltar devido ao inchaço das pernas e pés, da difícil respiração e do cansaço que vem mais rápido. Estes e muitos outros fatores, como a preocupação com o parto, costumam esfriar novamente a relação (6).

Assim, a gravidez é considerada para muitas mulheres um momento especial, mas nem todas têm o mesmo pensamento. Para algumas, esta fase da vida pode gerar sentimentos não positivos, e para isso é necessário considerar que existem inter-relações entre transformações gestacionais, auto-imagem e auto-estima feminina $(2,5)$.

São inúmeras alterações que envolvem mecanismos de adaptações anatômicas, fisiológicas e bioquímicas no curto intervalo de tempo gestacional. As adaptações referidas estão diretamente ligadas à circulação sistêmica e uterina, ao metabolismo e às necessidades nutricionais do corpo, que em cascata repercutem em outros sistemas $(6,9)$.

Desta forma, fica claro que há necessidade de saber mais sobre tais transformações que mexem tanto com o organismo e o funcionamento desta mulher. São, em nosso entendimento, indispensáveis para que possamos cuidar destas mulheres de modo humanizado. Esse cuidado oportunizará despreocupar as mulheres quanto ao que lhes acontece no corpo e na vida e ajudá-las a vivenciar de modo pleno e prazeroso sua gravidez $(8,10)$. Portanto este estudo mostra-se relevante, por trazer a perspectiva da mulher sobre sua vivência e seus significados, o que é fundamental para o cuidado humanizado.

Nesse contexto, interessou-nos investigar as transformações vivenciadas pela mulher no período gestacional. Assim, a questão norteadora deste estudo foi: o que significa para a gestante as transformações que acontecem com seu corpo e em sua vida decorrentes da gravidez. Definimos como objetivo identificar o significado das transformações do período gestacional, sob o ponto de vista da gestante, que influenciam em sua identificação como mãe.

Há relevância neste estudo pela necessidade de se descrever como a gestante significa para si mesma o fato de estar gerando um novo ser. Desse modo seus resultados podem ser considerados importante colaboração para a prática do enfermeiro no cuidado humanizado à mulher e sua família durante o ciclo gravídico-puerperal. Este, ao perceber os sentimentos e as transformações vivenciadas pelas mulheres na gestação, como caminhos para o autoconhecimento, como instrumentos de reflexão de conceitos, valores e conflitos, poderá gerar cuidado e assistência de enfermagem, direcionados e de uma forma diferenciada, respeitando desde a questão do gênero até a fisiologia materna $(11,12)$, valorizando a dignidade dos sujeitos, principalmente nesta fase única da vida. O conhecimento adquirido com esta pesquisa poderá complementar a assistência de enfermagem às gestantes, contribuindo de maneira significativa para um melhor planejamento do cuidado.

\section{MÉTODO}

Trata-se de um estudo qualitativo desenvolvido com base nos pressupostos do Interacionismo Simbólico e da Grounded Theory.

O Interacionismo Simbólico caracterizase por ressaltar o valor do sentido dos objetos, seres humanos, instituições, dentre outros para o comportamento humano. São três seus princípios fundamentais:

$\mathrm{O}$ ser humano age com relação às coisas na base dos sentidos que elas têm para ele; o 
sentido destas coisas é derivado, ou seja, da interação social que alguém estabelece com seus companheiros; e estes sentidos são manipulados e modificados através de um processo interpretativo (9).

O interacionismo simbólico é uma teoria que analisa o homem nas interações dentro de seu contexto social, conserva os processos dinâmicos entre as pessoas, enfatizando o caráter imprevisível do ser humano, e busca interpretar o sentido que advêm das interrelações pessoais $(13,14)$.

A Grounded Theory, fundamentada no Interacionismo Simbólico, focaliza os fenômenos e os significados destes para os sujeitos da pesquisa (15).

As informações, conceitos e explicações vão se criando ao longo da pesquisa, ou seja, o pesquisador não tem nenhum dado, nem conceito já elaborado, e este vai sendo estruturado com o desenvolvimento da coleta de dados (15).

Sabe-se que o "objetivo de se proceder à coleta e à análise dos dados simultaneamente é para se gerar uma teoria baseada nos dados empíricos"(16). O pesquisador só cessa a coleta dos dados quando não se obtêm dados diferentes ou novos, no momento em que houver saturação das categorias.

Tem-se conhecimento de que o pesquisador, ao codificar e analisar dados identifica padrões e compara incidente com incidente, incidente com categoria e construto com construto (16).

O estudo foi submetido ao Comitê de Ética em Pesquisa do Hospital Universitário Pedro Ernesto, que aprovou o projeto (protocolo: 1125-CEP/HUPE), conforme Resolução No 196 de 10 de outubro de 1996, do Conselho Nacional de Saúde.

Os sujeitos da pesquisa foram onze mulheres no segundo ou terceiro trimestres da gravidez. Esta escolha se deu pelo fato de considerarmos que estas trariam experiências sobre as mudanças gestacionais já vivenciadas nos primeiros meses de gestação e suas implicações emocionais e físicas. Todas estavam inclusas no pré-natal de um Centro Municipal de Saúde do Município do Rio de Janeiro, mulheres de classe social menos favorecida, jovens, algumas primíparas e outras multíparas, casadas, solteiras, do lar ou com uma profissão estabelecida, mulheres que desejavam engravidar e outras, porém que não tinham esta ambição para o momento atual. Embora reconheçamos importantes as influências socioculturais e contextuais na vivência de situações de interação dos indivíduos com seu meio, estas não foram aqui tomadas como premissas por entendermos que o significado a ser estudado poderia ser adquirido sem deixar estes fatores isoladamente $(17,18)$.

A técnica utilizada para coleta de dados foi a entrevista semi-estruturada, aplicada após as gestantes assinarem o Termo de Consentimento Livre Esclarecido. A coleta de dados foi realizada no primeiro trimestre de 2005. Os pesquisadores gravaram todas as entrevistas e as transcreveram. A entrevista teve como ponto de partida a frase: "fale-me sobre as transformações vivenciadas nesta gestação". De acordo com a Grounded Theory, a análise comparativa constante dos dados indica que novos grupos amostrais devem ser incluídos e, dessa forma, que novos conjuntos de dados devem ser obtidos $(15,19)$. Por esta razão, a inclusão das informantes foi sendo feita à medida que se desenrolava o processo de coleta e análise das entrevistas anteriores.

O processo de análise desenvolveu-se nas seguintes etapas: transcrição das entrevistas, realizada pelos próprios pesquisadores/ entrevistadores, mantendo-se na íntegra os depoimentos; distribuição vertical e sequencial do discurso, quando os pesquisadores separam o discurso linha por linha de modo a permitir a codificação aberta $(15,19)$; codificação substantiva ou codificação aberta, etapa em que a cada linha do discurso é atribuído código que procura representar seu significado; agrupamento de códigos afins, que permitiu a construção de categorias 
provisórias; categorização preliminar etapa em que os pesquisadores, através da comparação constante entre os dados, identificam categorias e suas dimensões para posterior consolidação; análise e consolidação das categorias construídas preliminarmente; e, por fim, identificação da categoria central (17, 19). Em seguida elaborou-se um diagrama representativo deste processo social $(15,17$, 19), visualizado na Figura 1. Assim, a categoria central identificada como sendo, vivenciando repercussões e transformações de uma gestação, emergiu da comparação/integração entre as demais categorias e caracteriza o processo pelo qual está passando a gestante em suas relações com seu meio social.

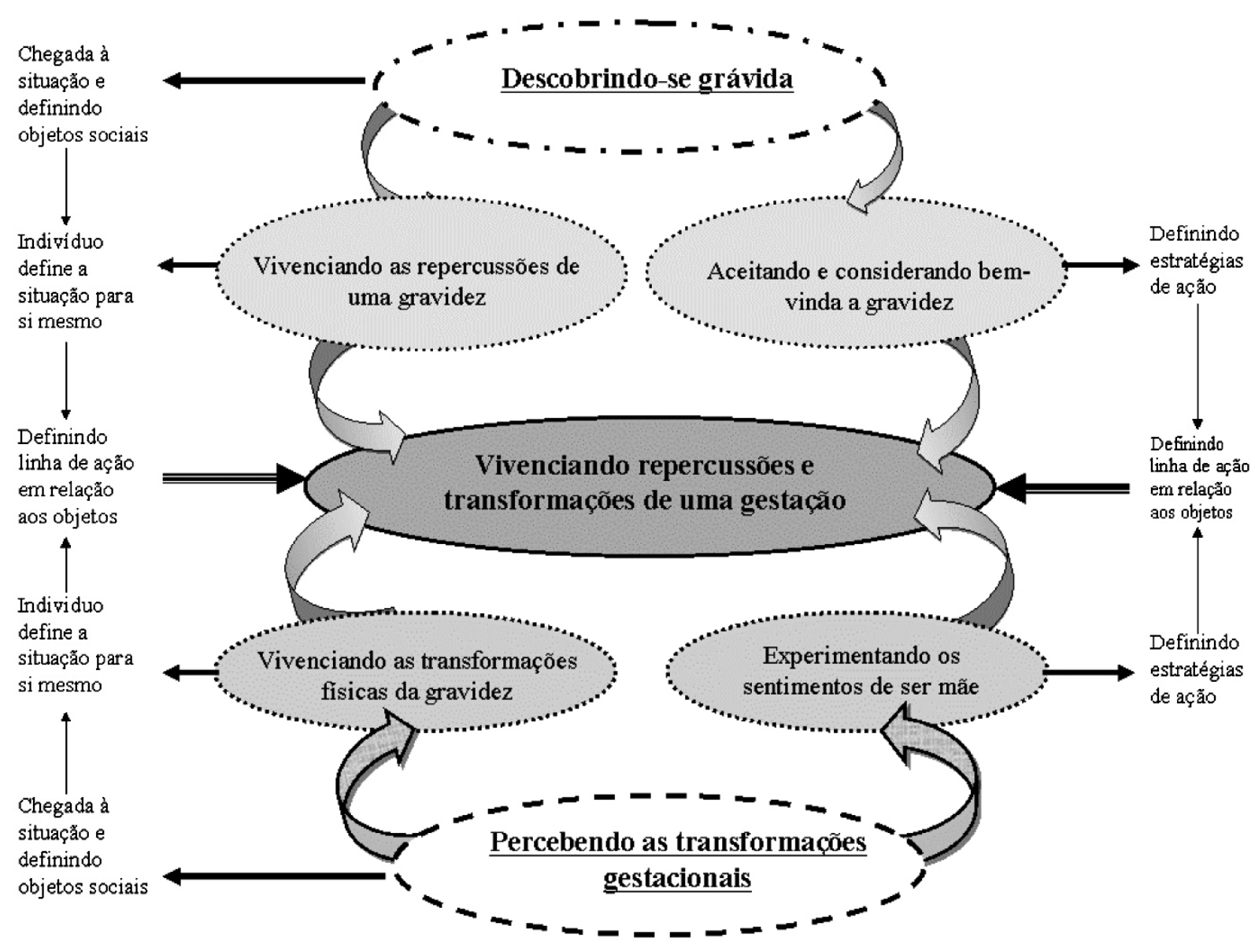

Figura 1. Correlação entre as Categorias.

\section{RESULTADOS E DISCUSSÃO}

Charon (19) ao explicar a ação humana na perspectiva interacionista dentro de uma situação real, detalha as fases que o indivíduo precisa transcorrer para atingir uma tomada de decisão. O conjunto de fases descritas por este autor pode ser assim sintetizado: inicialmente o indivíduo chega a uma determinada situação trazendo consigo seu self, a mente, símbolos, perspectivas e suas 
referências de grupos. Uma vez tendo entrado na situação o passo seguinte é a definição desta para si mesmo. É caracterizada como o momento em que o indivíduo identifica e define os objetos sociais presentes, define também metas, aplica perspectivas apropriadas, procura colocar-se no papel dos outros na situação, aplica experiências passadas estabelecendo relação com o presente, considera o futuro e novamente olha a si mesmo na situação. E por fim, este indivíduo torna-se capaz de determinar a linha de ação e agir em relação aos demais objetos sociais presentes, incluindo-se aí os demais indivíduos.

Neste sentido, para estas gestantes, o vivenciar da gravidez englobou três grandes dimensões, representadas pelas categorias: descobrindo-se grávida, percebendo as transformações gestacionais e, por fim, a categoria central: vivenciando repercussões e transformações de uma gestação.

\section{Descobrindo-se grávida}

O primeiro ponto de encontro com a gestação está em descobri-la. Esta descoberta caracteriza a chegada deste indivíduo, a gestante, a uma situação de interação social determinada (15): a gravidez. Eis um momento significante de transição e de identificação, conceber que um novo ser está sendo gerado e este, por sua vez, torna-se capaz de transformar de alguma maneira a vida da mulher e também de todos que a cercam. Independentemente de a gestação ser ou não planejada, esta suscita transformações físicas e psicossociais intensas (20).

Para a gestante, estar grávida engloba uma ambivalência, mistura dos sentimentos de querer e não querer - é a vivência básica da gravidez (21). Corresponde ao momento em que a gestante se vê definindo para si mesma a situação na qual se encontra (15, 17), e engloba o vivenciar as repercussões desta gravidez e culmina pela aceitação desta.

\section{Vivenciando as repercussões de uma gravidez}

A confirmação da gravidez desencadeia um processo de reorganização da percepção de si e de sua relação com o mundo que a cerca. A mulher começa a conviver com a idéia de estar grávida, e com isso há o envolvimento de um repertório de elementos internos desta mulher, como seu self, os símbolos com os quais identifica a situação de ser mulher grávida, perspectivas e referências de seu grupo social próximo, o que acaba interferindo na vivência das repercussões da gravidez.

Nessa condição, uma gravidez não planejada, ou não desejada, pode gerar distintos sentimentos na gestante. $\mathrm{O}$ fato de não ter sido planejada, implica direta e indiretamente numa surpresa iminente, quer seja esta positiva ou negativa. Quando o diagnóstico da gestação é confirmado pode provocar maiores emoções: desde alegria e bem estar intensos até a tristeza profunda e sensação de desamparo.

A gestação não planejada pode trazer dentre alguns sentimentos: culpa, frustração e vergonha $(1,22,23)$.

[...] ] gravidez não estava programada. No início foi um choque. (gestante 02)

É, no começo é complicado até você aceitar a gestação é complicado. Sempre a culpa é nossa de ter engravidado. (gestante 06)

Descobrir-se grávida repercute também em como será criar um novo ser. Há repercussões diretamente ligadas às condições socioeconômicas e culturais da mulher(24).

No comecinho[...] Veio todo mundo em cima de mim falando que eu já tinha dois filhos e estava grávida de novo[...] As pessoas ficavam me culpando, situação difícil de criar os filhos, de viver[...] (gestante 01)

Outro fator que interfere na relação da mulher com o fato de estar grávida é a ida- 
de. De modo geral a mulher que ultrapassou determinada idade cronológica não deveria mais estar ocupada com a reprodução, exceto para evitar a gravidez. Esta é uma idéia presente na sociedade e que, de certo modo, pode fragilizar mulheres que engravidam quando já não se espera que mulheres engravidem (24). Este pensamento representa e consolida a visão social da idade reprodutiva (7).

[...] já tenho 2 filhos na vida difícil, vem às críticas, estou com 36 anos, e não era mais para ter filhos, mas netos. (gestante 12)

Algumas relataram que a reprodução não era uma prioridade em suas vidas.

Eu estou casada há seis anos, mas neste tempo nunca quis engravidar. Eu trabalho muito, a gravidez não estava nos meus planos [...] Não tinha planejado, nem pensava de longe em engravidar. (gestante 07)

Engravidar inesperadamente pode gerar sentimentos confusos na mente materna, podendo ser comparada a uma invasão, como algo que se instala sem pedir permissão. Neste contexto a mulher começa a definir a situação real para si mesma, de que está grávida. Após este entendimento de si mesma a gestante procura determinar metas no sentido de levar ou não a gravidez adiante, aplicando perspectivas apropriadas $(9,15,17)$.

Uma perspectiva percebida neste estudo foi o processo de aceitação da gravidez independente de ter sido desejada ou não, pois para que esta prossiga, a mulher decidiu, pelo menos, aceitá-la, pois não escolheu a interrupção.

\section{Aceitando e considerando bem vinda a gravidez}

Com o desenvolvimento da gravidez, aos poucos, transforma-se um ambiente inicialmente marcado pelo não desejo em um uni- verso de aceitação. Mais uma vez caracterizase por uma mistura de sentimentos de tensão e carinho que repercutem na concepção bem vinda da gestação. Isso acontece, pois a gestante neste momento passa a olhar a si mesma na situação e projetar o futuro.

Eu não pensava, não queria mesmo, não estava nos meus planos, mas com o desenvolver da gestação, não tinha como não aceitar, pensava no bebê que estava por vir. (gestante 07)

E mesmo nos casos em que a gestação é desejada, ela também traz sensação de apreensão e de dúvida, receio, mas também carregada do sentimento de amor que valoriza o instinto e dá resposta às expectativas sociais (25).

Bom, eu desejava a gestação, mas não estava planejando não. Eu fiquei meio receosa [...], mas agora eu estou feliz. (gestante 11)

Eu acho que toda mulher tem que ter filhos [...], porque é muito bom. Mas também é confuso e dá um frio na barriga. (gestante 05)

A gravidez desenvolve-se melhor quando a mulher recebe apoio e atenção, trazendo momentos de felicidade, não somente para ela, como também para todos que a cercam. Este fato deve-se também a fatores emocionais que interferem diretamente na concepção da gestação, pois além de gerar um novo ser, gera-se também uma mulher mãe que nunca havia sentido sentimentos dessa natureza, que não intensos e transformadores $(2,4,7)$.

Segundo Charon (19), neste momento a gestante, por conseguir olhar para si mesma na situação, pode então perceber de modo mais ativo as transformações em seu corpo.

\section{Percebendo as transformações gestacionais}

Em nosso estudo, o descrito na categoria anterior dizia respeito às mudanças acontecidas na dimensão subjetiva das relações, porém as 
transformações físicas também são responsáveis por muitas mudanças na organização corporal e também no comportamento. Assim, o que o que estamos discutindo nesta categoria diz respeito à relação com o corpo físico, biológico, em sua dimensão objetiva, concreta, e as repercussões destas na vida da mulher.

Diversos fatores estão em transformação no corpo e, por conseqüência, no cotidiano e na relação da mulher com seu meio. A experiência gestacional é uma mescla orgânica e psicossocial intensa que implica em mudanças na imagem corporal, hormônios, identidade e no vínculo com o parceiro (20), ou mesmo com seu ambiente familiar.

Assim, para a gestante o descobrir-se na situação de estar grávida passa pela percepção e reconhecimento destas adaptações que ocorrem em seu corpo e de como elas vão interferir na sua vida. Constitui, portanto uma maneira diferente, mas não isolada, de chegar à situação e, por conseguinte, uma perspectiva também diferente de identificar e definir a situação para si, caracterizar e definir os objetos sociais presentes, aplicar perspectivas de grupo e experiências passadas que permite projetar o futuro e se permitir viver o presente, neste caso permitir-se vivenciar as transformações gestacionais.

\section{Vivenciando as transformações físicas da gravidez}

A construção do ser mãe é realizada a cada dia, o corpo molda-se em novas formas. Surgem os primeiros sintomas positivos da gravidez: enjôos, fraqueza, desmaios, cefaléia, náuseas, seios fartos (6). É desta maneira que a mulher vai se adaptando aos seus novos formatos e às diferentes sensações orgânicas. Esta é a etapa de considerar o futuro e de olhar a si mesma na situação (19).

No começo eu enjoei um pouquinho, não podia usar nada que enjoava [...] Dava aquela vontade de vomitar. (gestante 10)
Acho essa barriga grande, meu nariz gordo, varizes, ah não! [...] Eu só me vejo essa barriga. (gestante 07)

As alterações fisiológicas na gestação podem ser consideradas as mais significativas mudanças que o corpo humano sofre, implicando em adaptações fisiológicas e psicossociais que ajudam a mulher a adaptar-se à gravidez, manter sua saúde durante toda a gestação e preparar-se para o momento do nascimento de seu filho (2).

Um fator observado foi que as gestantes multíparas têm na relação consigo mesmas um pouco mais de conformação das transformações gestacionais do que as primíparas.

[...] Assim, em relação à barriga, eu sinto que está crescendo menos do que a outra vez [...] Para mim foi só a barriga mesmo que mudou. Não senti mais nada de diferente nesta gestação. (gestante 03)

Quando se trata de primípara as transformações afetam mais a auto-imagem e a auto-estima. As transformações fisiológicas e psicológicas apesar de serem necessárias, podem ser consideradas desfavoráveis e até mesmo geradoras de medo nestas gestantes.

Eu senti que meu peito cresceu bastante, as pernas incharam[...] Comecei a não pensar só em mim, agora penso por dois, né! Para falar a verdade, eu me senti mais importante, me senti mais bonita e mais sensual também. (gestante 04)

Estas transformações também podem afetar a vida sexual do casal, pois as mudanças físicas e emocionais interferem na condução da sexualidade. O desejo sexual está presente e em alguns casos mais aguçado. No entanto para algumas gestantes surgem dificuldades para manter a atividade sexual pelo desconforto físico ou pela sensibilidade aumentada que exige um carinho e cuidado do parceiro 
de forma mais expressiva. É necessário criar formas adaptativas para sentir prazer $(12,26$, $27,28,29,30)$.

Na gravidez muda [o sexo] quando a barriga começa a ficar grande porque aí atrapalha, dá um desconforto [...], eu desejo que ele seja mais delicado, cuidadoso, sensivel, que cuide de mim neste momento de uma forma diferente. (gestante 02)

Se a gestante não estiver preparada ou até mesmo bem informada sobre as mudanças pelas quais seu organismo passará, a gravidez pode não ser conduzida de maneira prazerosa, tornando-se algo diferente do idealizado no subjetivo mais íntimo da mulher. Neste processo é comum a aplicação de experiências passadas (19) ou experiências de grupo, incluindo familiares próximos.

\section{Experimentando sentimentos de ser mãe a partir das mudanças no corpo}

Os sentimentos da maternidade foram relatados principalmente por primíparas, para quem estes foram aflorando juntamente com a gestação. As grávidas que já têm outros filhos não se preocuparam em relatar experiências quanto ao ser mãe.

É sabido que durante a gestação, a identidade materna é construída por meio de uma imagem idealizada de si como mãe e, também, do bebê como filho (31). E assim ao longo dos meses da gravidez esta mulher vai experimentando o sentimento de ser mãe e ao mesmo tempo criando sua identidade materna.

É uma coisa estranha [...] Eu acho que tenho medo de não ser uma boa mãe, tenho medo de errar [...] tenho medo de ser diferente da minha mãe, que eu tenho como modelo de mãe, mas a cada dia eu me percebo um pouquinho mais mãe e mais responsável com este bebê. (gestante 09)
O significado das transformações, do período gestacional sob o ponto de vista da mulher, está em perceber cada emoção, conectada com cada nova mudança percebida no corpo, como parte integrante desta fase da vida. A forma como a gestante reage a estas transformações tem implicações diretas em seu adaptar-se e em sua identidade de mãe.

Quando a gestante chega à etapa de determinação de uma linha de ação em relação aos objetos sociais presentes na situação, decide então vivenciar as repercussões e transformações da gestação, e que caracterizou a categoria central do presente estudo (19).

\section{Vivenciando repercussões e transformações de uma gestação}

A análise dos dados e a correlação com o modelo teórico explicativo da ação humana, segundo a perspectiva interacionista, conforme proposto por Charon (19) nos levaram a entender a relação existente entre as categorias que encontramos neste estudo. Segundo esta perspectiva o indivíduo chega à situação, ao alvo de suas inquietações, mas traz consigo muitos fatores internos que diretamente permitem direcionar para uma tomada de decisão que é a delimitação da linha de ação.

Seguindo este esquema, Descobrindo-se grávida simboliza o desabrochar da gestação, revelando o primeiro contato com o universo do gerar um novo ser. Esta fase, de acordo com os pressupostos de Blumer (17), é o que chamamos de chegada à situação, onde o indivíduo define a situação para si mesmo. A confirmação da gestação pode despertar na mulher diversos sentimentos, permitindo-a vivenciar este momento exclusivamente feminino. Nesta etapa, a mulher aplica experiências passadas, perspectivas apropriadas, define metas e considera o futuro (9) para dessa forma articular elementos internos com fatores externos visualizados e experimentados.

A confirmação desta informação, gravidez, conduz a mulher a buscar recursos para 
vivenciar esta nova realidade em sua vida, correspondendo ao segundo passo da ação humana na perspectiva interacionista, que é a determinação da linha de ação em relação aos objetos sociais por ela identificados (17).

O terceiro passo segundo a perspectiva do interacionismo simbólico seria determinar a linha de ação em relação aos objetos, incluindo também outros indivíduos (19).

E, além disso, é necessário que a mulher interprete seus próprios atos, determine seus significados. Isto corresponde à fase em que o indivíduo compreende seus próprios atos à luz da ação dos outros e interpreta a ação dos outros (17). Neste caso a gestante ativamente precisa tomar a iniciativa pessoal de decidir por adaptar-se.

A partir da integração das categorias foi possível visualizar que a vivência das transformações depende de como a gestante se vê como mulher e mãe, e também da interação de seu grupo social, e deste com o meio externo. Podemos, ao final de nossa análise, evidenciar os diversos modos de vivenciar a gestação pela mulher durante esse período e descrever, segundo a visão interacionista da ação humana, o processo de interação da gestante face às mudanças promovidas pela gravidez em sua vida.

\section{CONSIDERAÇÕES FINAIS}

O processo da gestação é complexo, dinâmico e transformador. Vivenciar este processo significa entender a gravidez como um fenômeno de dimensões sócio-culturais, além da dimensão física marcada pelas transformações do corpo.

No âmbito da subjetividade o descobrirse grávida, vivenciar as repercussões de uma gravidez em seu meio e aceitá-la, leva à primeira decisão da gestante: levar a diante a gestação e não optar pela interrupção. Ao tomar esta decisão a gestante se permite então reconhecer e vivenciar as transformações ob- jetivas em seu corpo físico e o impacto destas em sua relação de interação com seu grupo social próximo.

A enfermeira, ao compreender essa dinâmica relação da mulher e seu grupo com a gravidez, tem em mãos instrumentos fundamentais para o desenvolvimento de uma prática humanizada. Ao adotar esta prática estará agindo em consonância com as recomendações da Organização Mundial de Saúde relacionadas à Maternidade Segura.

\section{REFERÊNCIAS}

1. Costa MCO, Lima, IC, Martins Júnior DF, Santos CAST, Araújo FPO, Assis DR. Ciênc. saúde coletiva. 2005; 10(3): 719727.

2. Moura ERF, Silva RM. Assistência humanizada ao parto a partir de uma história de vida tópica. Acta Paul. 2006; 17(2): 141-7.

3. Branden PS. Enfermagem materno-infantil. 2a ed. Rio de Janeiro: Reichmann \& Affonso editores; 2000.

4. Camacho KG, Vargens OMC, Progianti JM. Adaptando-se à nova realidade: a mulher grávida e o exercício de sua sexualidade. Rev. enferm. UERJ. 2010; 18(1):32-37.

5. Freitas F, Costa SHM, Ramos JGL, Magalhães JA. Rotinas em obstetrícia. 2 a ed. Porto Alegre: Artmed editora; 2003.

6. Neme B. Obstetrícia básica. 3a ed. São Paulo: SAVIER; 2006.

7. Luz AMH, Berni NIO, Selli L. Mitos e tabus da maternidade: um enfoque sobre o processo saúde-doença. Rev Bras Enferm. 2007; 60(16):42-8.

8. Lupton D. Corpos, prazeres e a prática do eu. Revista Educação \& Realidade. 2000; 25(2):15-46.

9. Blumer H. Symbolic interactionism: perspective and method. London (UK): 
University of California Press; 1969.

10. Souza LB, Fernandes JFP, Barroso MGT. Sexualidade na adolescência: análise da influência de fatores culturais presentes no contexto familiar. Acta Paul Enferm. 2006; 19(4):408-13.

11. Scott J. Gênero: uma categoria útil para a análise histórica. Educação \& Realidade. 2008; 20(2): 86.

12. Maturana HC, Progianti JM. A ordem social inscrita nos corpos: gravidez na adolescência na ótica do cuidar de enfermagem. R Enferm UERJ. 2007; 15(2): 205-9.

13. Bazilli C. Interacionismo Simbólico e Teoria dos Papéis: uma aproximação para a psicologia social. São Paulo: EDUC; 1998.

14. Carvalho LS, Silva CA, Oliveira ACP, Camargo CL. O interacionismo simbólico como fundamento para pesquisas de enfermagem pediátrica. Rev enferm UERJ. 2007; 15:119-24.

15. Stern PN. Grounded Theory Methodology. It uses and processes. Image. 1980;12(1);20-3.

16. Merigi MAB, Praça NS. Abordagens teórico-metodológicas qualitativas. A vivência da mulher no período reprodutivo. Rio de Janeiro: Guanabara Koogan; 2003. Pp. 40-41.

17. Glaser, BG. The Grounded Theory Perspective: conceptualisation contrasted with description. California: Sociology Press, Mill Valley; 2001.

18. Stern PN.Grounded theory methodology: its uses and process. Image. 1980; 12(1):20-3.

19. Charon, JM. Symbolic Interactionism: an introduction, an interpretation, an integration. 3a ed. Englewood Cliffs. Prentice Hall; 1989.

20. Ressel LB, Gualda DMR. A sexualidade na assistência de enfermagem: reflexões numa perspectiva cultural. Rev Gaúcha Enferm. 2004; 25(3):323-33.

21. Maldonado MT. Recursos de relaciona- mento para profissionais de saúde: a boa comunicação com clientes e seus familiares em consultórios, ambulatórios e hospitais. Rio de Janeiro: Reichmann \& Affonso editores; 2003.

22. Fernandes JFP, Souza LB, Barroso MGT. Repercussões da gravidez no contexto sócio-familiar da adolescente - uma experiência. Acta Paul. Enf. 2004; 17(4):4006.

23. Padilha MIt CS, Helena HV, Gladys B. Gênero e enfermagem: uma análise reflexiva. Rev enferm UERJ. 2006; 14(2):292300.

24. Pereira CRR; Piccinini CA. O impacto da gestação do segundo filho na dinâmica familiar. Estud. psicol. 2007; 24(3): 385395.

25. Pellegrini JO. A Sexualidade na Gestação. Revista da Federação Brasileira das Sociedades de Ginecologia e Obstetrícia. 2003; 31(1):79-82.

26. Zeglio C, Rodrigues J, Oswaldo M. Amor e sexualidade: como sexo e casamento se encontram. São Paulo: Iglu; 2007.

27. Oriá MOB, Alves MDS, Silva RM. Repercussões da gravidez na sexualidade feminina. Rev enferm UERJ. 2004; 12(2):1605.

28. Trindade WR, Ferreira MA. Sexualidade feminina: questões do cotidiano das mulheres. Texto Contexto Enferm. 2008; 17(3): 417-26.

29. Ressel LB, Gualda DMR. A sexualidade na assistência de enfermagem: reflexões numa perspectiva cultural. Rev Gaúcha Enferm. 2004; 25(3):323-33.

30. Gomes MEA, Silveira LC, Petit SH, Brasileiro GM V, Almeida ANS. A sexualidade das mulheres atendidas no programa saúde da família: uma produção sociopoética. Rev Latino-am Enfermagem. 2008; 16(3): 382-8.

31. Marasinghe JP, Karunananda SA, Amarasinghe AA. The mature gravida: a different approach. Eur J Obstet Gynecol Reprod Biol; 2007; 135(1): 136. 